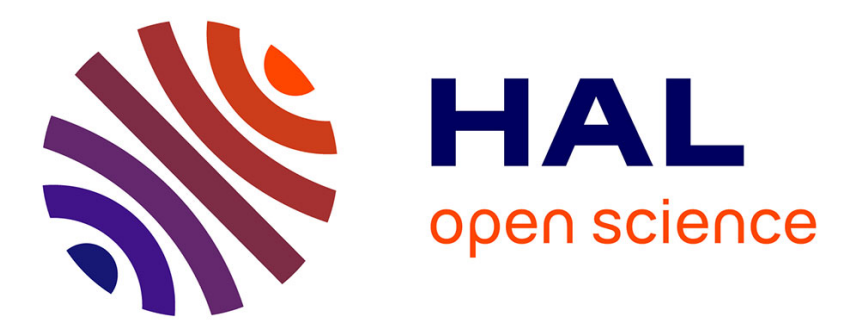

\title{
The impact of asymmetric regulation on surplus and welfare: the case of gas release programmes
}

\author{
Cédric Clastres, Laurent David
}

\section{To cite this version:}

Cédric Clastres, Laurent David. The impact of asymmetric regulation on surplus and welfare: the case of gas release programmes. OPEC Energy Review, 2009, XXXIII (2), pp.97-110. halshs-00442213

\section{HAL Id: halshs-00442213 https://shs.hal.science/halshs-00442213}

Submitted on 18 Dec 2009

HAL is a multi-disciplinary open access archive for the deposit and dissemination of scientific research documents, whether they are published or not. The documents may come from teaching and research institutions in France or abroad, or from public or private research centers.
L'archive ouverte pluridisciplinaire HAL, est destinée au dépôt et à la diffusion de documents scientifiques de niveau recherche, publiés ou non, émanant des établissements d'enseignement et de recherche français ou étrangers, des laboratoires publics ou privés. 


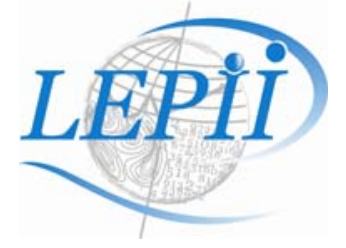

\section{LABORATOIRE D'ECONOMIE DE LA PRODUCTION \\ ET DE L'INTEGRATION INTERNATIONALE}

UMR 5252 CNRS - UPMF

\section{CAHIER DE RECHERCHE}

$\mathrm{N}^{\circ} 20$

\section{A surplus and welfare analysis of asymmetric regulation}

Cédric Clastres ${ }^{1,2}$

Laurent David ${ }^{3}$

avril 2008

${ }^{1}$ Grenoble Electrical Engineering (G2ELAB) - INPG, UJF, CNRS

${ }^{2}$ LEPII-UPMF, CNRS

${ }^{3}$ Gaz de France, division Recherche 

A surplus and welfare analysis of asymmetric regulation ${ }^{1}$

Cédric CLASTRES

Grenoble Institute of Technology - G2ELab - ENSIEG

UPMF - LEPII - EREN

cedric.clastres@g2elab.inpg.fr

Laurent DAVID

Gaz de France - Resarch Division

361 av. du president Wilson - BP 33 - 93211 La Plaine Saint Denis

laurent-m.david@gazdefrance.com

April 2008

Abstract

Some European regulators have decided to force competition in their national markets. They have decided to go beyond the second directive and apply asymmetric regulation. Gas release programs and market shares constraints are the two asymmetric decisions imposed to incumbents. When a regulator imposes a gas release program to an incumbent, this operator is compelled to release quantities of its long term contracts to its competitor. In this paper, we will focus on gas release and its impact on welfare, consumer surplus and on the level of released quantities set by regulators.

The aim of a gas release program is to give access to natural gas to competitors. They become actives on the market and are in competition with the incumbent. These programs are time limited. They only help competitors in expecting the development of hubs or new investments in importation infrastructures. If competitors want to stay active after the program, they may find others supply sources to increase security of supply.

The gas release can induce Raising Rival's Costs or "Self-Sabotage" strategies. We use a Cournot model with capacity constraints to answer two questions.

First, we will study the impact of these strategies on consumer surplus and welfare. We will show that there are no impact on consumer surplus but the welfare decreases. The gas release program introduces a transfer of profit between competitor and incumbent, reduces welfare because of the increase in costs of supply, but has no impact on total consumed quantities.

Then, we will suppose that the regulator is setting released quantities maximising welfare. Gas release price is often based on costs plus a bid or a fixed premium. Quantities are set with a less obvious process. We will demonstrate that the regulator must set released quantities :

- that would not be so high if incumbent's supplies are small to avoid SelfSabotage or RRC strategies;

- as a function of incumbent's supplies if they are in intermediate values to avoid strategies seen above and to optimise quantities sold on the market;

\footnotetext{
${ }^{1}$ We are very grateful to Gaz de France for their financial support and to Pr. J. Percebois, E. Baranes, Y. Smeers, C. Crampes, J-C Poudou and f. Mirabel for their helpful comments, ideas and discussions. The usual caveat applies. The positions expressed in this paper are not official positions of Gaz de France.
} 
- at a sufficient level to let the two operators playing their Cournot best reply function.

Finally, we will conclude that the regulator can avoid RRC or Self-Sabotage strategies in maximising the welfare when it decides gas released quantities. Gathering from empirical studies, these quantities should not be so high in order to let a significant difference between the capacities of both competitor and incumbent to avoid collusive behaviours.

Keywords: Energy market; Gas release; Regulation; Optimal released quantities; Efficiency; Welfare

JEL Classification : L13, L29, L51, L95

\section{Introduction}

The european commission has published a lot of directives to open gas and electricity markets to competition (Green [2007]). With the deregulation of European energy markets, some regulators have decided to implement asymmetric regulation. Schankerman (1996) defined a symmetric regulation like a regulation that gives to all participants to the market the same rules to make competition. Each of them must receive the same price signal and must respect the same obligations and restrictions. Starting from this definition, we can define an asymmetric regulation as a set of regulation rules that apply to one or some operators. The aim of this regulation is to promote entries of competitors by an easier access to the commodity.

Asymmetric regulations have been implemented by some regulators in several network industries. In telecommunication market, incumbent must serve the local service and long distance call at a regulated price. Competitors could propose a smaller price than incumbent one and it could gain customer with this strategy of cream-skimming. In electricity market, incumbent must release part of their generation capacity. For example, ENEL (3700 MW in the Sourthern Italy macro-zone and 150 MWin the Sicily macro-zone) and EDF (1025 MW by auctions, 736 MW baseload et 289 MW peakload in september 2007) have sold capacities of production in Virtual Power Plants mechanism. In gas market, some regulators have implemented gas release programs. The incumbent must release part of its supplies contracted by long term relations to its competitors (in France, gas release of 45 TWh by auctions and over the counter negociation).

In this paper, we will focus on asymmetric regulation in European gas market. Clastres and David (2005) have shown that incumbent can have incentives to increase its cost of supply to reduce competitor's sales. Doing so, the incumbent increases its profits. in this paper, we will show the impact of gas release program on consumers' surplus and welfare and that this strategy has no impact on consumer surplus but decreases welfare.

European gas release experiences show that gas release prices are often set in line with the incumbent's importation costs, at the weighted average cost of 
gas or by auctions with ceiling price. Price setting mechanism is known by all participants. Few information is available on gas release proportion setting.

Gas release quantities are set in a less obvious process. We will show that the regulator can set the gas release proportion to maximise welfare. The only condition is to know the incumbent supplies.

\section{Presentation, strategies and equilibriums of the Cournot game}

We start from Clastres and David's model (2005). An integrated firm has bought a capacity of natural gas $K_{o}$ at unit cost $u$. This incumbent must offer a proportion $\alpha \in[0,1]$ of its capacity $K_{o}$ to its competitor on the downstream market at a price $r$. The incumbent is an upstream monopolist. However, because of gas release obligation, it cannot forclore its competitor. The competitor has choice to buy all or part of released quantities. The regulator determines both $\alpha$ and $r$ values. Variables $K_{o}, \alpha, u$ and $r$ are exogenous. Let $q_{o}$ and $q_{e}$ be the quantities respectively sold by the incumbent and its competitor. This Cournot game deals with two constraints. The competitor (or gas release) constraint $q_{e} \leq \alpha K_{o}\left(C_{1}\right)$ stipulates that it cannot sell more than the quantity it got from the incumbent. And the market constraint $q_{e}+q_{o} \leq K_{o}\left(C_{2}\right)$ that applies to both operators which cannot sell more than the incumbent's supplies. The demand function in the final market is a linear one, $P(q)=1-q$.

Profits are respectively for the incumbent and the competitor:

$$
\begin{gathered}
\Pi_{o}\left(q_{o}, q_{e}, r\right)=P\left(q_{o}+q_{e}\right) q_{o}-u K_{o}+r q_{e} \\
\Pi_{e}\left(q_{o}, q_{e}, r\right)=P\left(q_{o}+q_{e}\right) q_{e}-r q_{e}
\end{gathered}
$$

Authors found that the optimal solutions of the game are those of the simultaneous optimization program :

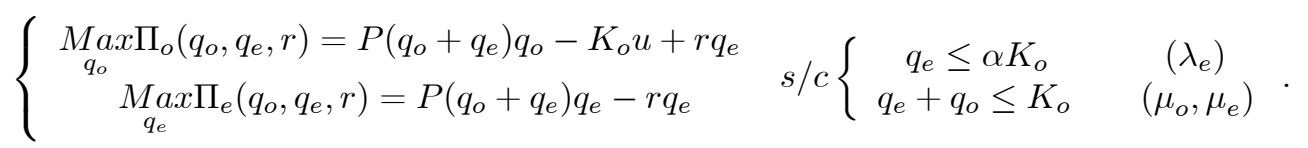

Let $\lambda_{e}$ be the multiplier value of $C_{1}$. Each firm has a multiplier value associated to $C_{2}$ (Breton and Zaccour [2001]). They are $\mu_{e}$ for the competitor and $\mu_{o}$ for the incumbent.

To solve this problem, we at first consider constraint $C_{1}$ and add in a second step constraint $C_{2}$. Four equilibriums are solutions of this maximization program. They depend on parameters $\alpha, K_{o}$ and $r$. We can represent these equilibriums in a $\left(K_{o}, \alpha\right)$ graph, for a given $r$. We have all different cases with the variation of $r$. Finally, we obtain four areas (see figure 1) where one equilibrium can be played by the two firms. 
In the zone $1 \mathrm{a}$, the two constraints are actives, so we have $\lambda_{e}=\frac{1}{2}-\frac{3}{2} \alpha K_{o}-$ $r>0$ and $\mu_{o}^{\kappa}=1+\alpha K_{o}-2 K_{o}>0$. The incumbent's supplies $K_{o}$ are too small to make the two constraints inactive. The equilibrium is :

$$
\left\{\begin{array}{l}
q_{e}^{\kappa}=\alpha K_{o} \\
q_{o}^{\kappa}=(1-\alpha) K_{o}
\end{array} .\right.
$$

In the zone $1 \mathrm{~b}, C_{1}$ is active $\left(\lambda_{e}>0\right)$. Within this zone, $\alpha$ is too small to allow the competitor to play its best-reply function; its best strategy is playing its maximum quantity. The incumbent, because of great values of its supplies, can play its best-reply function; $C_{2}$ is inactive. The equilibrium is :

$$
\left\{\begin{array}{c}
q_{e}^{\kappa}=\alpha K_{o} \\
q_{o}^{m}=\frac{1}{2}-\frac{1}{2} \alpha K_{o} .
\end{array}\right.
$$

In the zone $2, C_{2}$ is binding. This zone is characterized by a multiplicity of equilibriums (Breton and Zaccour (2001)). This equilibrium is :

$$
\left\{\begin{array}{l}
\widehat{q}_{e}=2 K_{o}+\widehat{\mu}_{o}-1 \\
\widehat{q}_{o}=1-\widehat{\mu}_{o}-K_{o}
\end{array} .\right.
$$

with $\widehat{\mu}_{o}=-3 K_{o}+2-r-\widehat{\mu}_{e}$ and $\widehat{\mu}_{e}>0$. We select one of these equilibriums by setting $\widehat{\mu}_{e}=0$. For gas industries, this choice is relevant insofar as the incumbent is in charge of the obligation of supply, the competitor puts no value on relaxing the market constraint. In this area, $\alpha$ is high enough to make $C_{1}$ inactive. Nevertheless, $C_{2}$ remains active because of the small incumbent's supplies.

In zone 3 , the two constraints are inactive. The two operators can play their best-reply function. This fourth equilibrium is the classic Cournot one:

$$
\left\{\begin{array}{l}
q_{e}^{c}=\frac{1}{3}-\frac{2}{3} r \\
q_{o}^{c}=\frac{1}{3}+\frac{1}{3} r
\end{array} .\right.
$$

All these curves are functions of $\alpha, K_{o}$ and $r$. They are drawn in a $\left(K_{o}, \alpha\right)$ plane for a given gas release price $\mathrm{r}$. If $\mathrm{r}$ changes, they all move except $\mu_{o}^{\kappa}$ that is constant in $\mathrm{r}$. If the gas release price increase, then the competitor will buy less gas release quantities. So, the gas release constraint will be inactive for a large range of $K_{o}$ or $\alpha$ values. Curves move towards the origin of axes. We will call $\left(K_{o}^{A}, \alpha^{A}\right)$ the coordinates of A point for a given gas release price $\mathrm{r}$.

Remark 1 All the four zones exist if $r \in\left[0, \frac{1}{2}\left[\right.\right.$. If $r \geq \frac{1}{2}$, then $q_{e}^{c} \leq 0$. In addition, the zones $1 a$ and $1 b$ disappear, and the Cournot equilibrium is not a feasible one. Then, only the zone of multiplicity of equilibriums can be reach. So, we will assume that $r \in] 0, \frac{1}{2}\left[\right.$. If $K_{o}>\frac{2}{3}-\frac{1}{3} r$ and $r>\frac{1}{2}$, then the competitor does not buy any quantity and the incumbent is in a monopoly configuration. In this case, the regulator does not implement a gas release program. As the gas release price is based on costs $u$, we can conclude that $u$ will be less than $\frac{1}{2}$. 


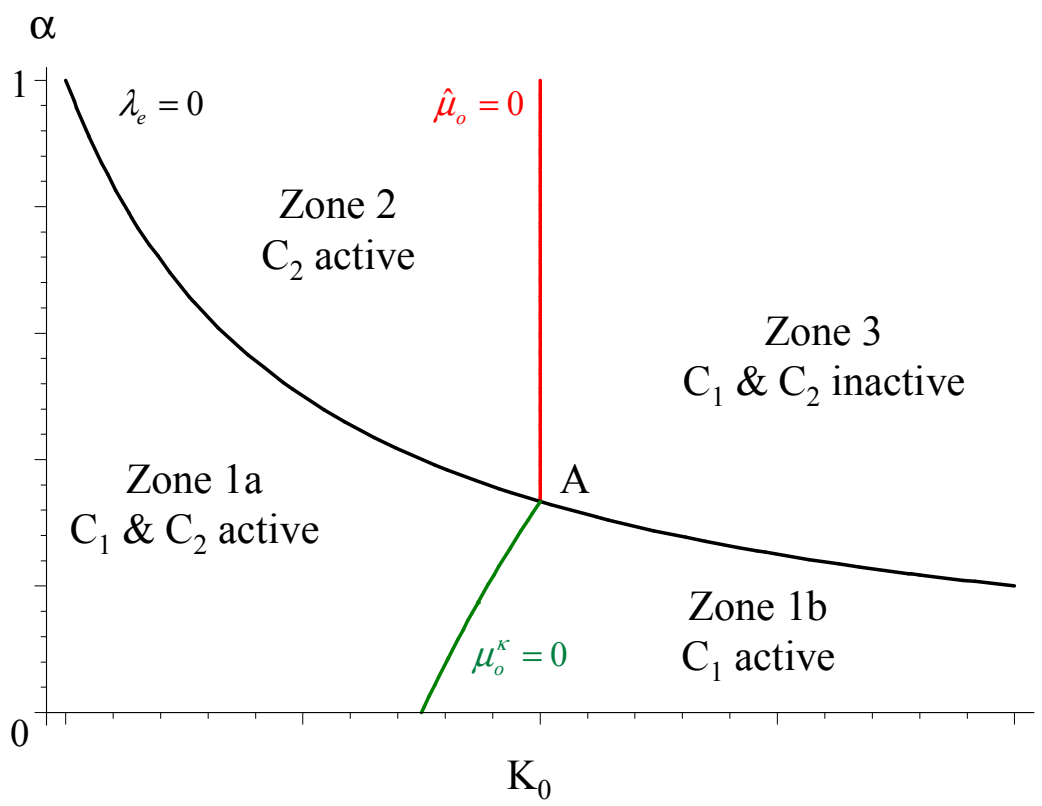

Figure 1: Four equilibriums zones

\section{Gas release influence on consumer's surplus and welfare}

\subsection{Gas release and consumer's surplus}

In Clastres and David (2005), we conclude that incumbent could have incentives to increase its costs to improve its profits on final market. These incentives depend on initial conditions $\left(K_{o}, \alpha, u\right)$. So, quantities sold on the market could increase or decrease if the equilibrium moves. These changes in quantities affect the consumers' surplus $S_{c}=\frac{1}{2} q^{2}$ with $q=q_{e}+q_{o}$ and $q>0$. Observing this surplus, we can see that more quantities on the market goes with an increasing surplus.

The consumers' surplus is the same when the market constraint $\mathrm{C}_{2}$ is active : $S_{c}^{\kappa}=\widehat{S}_{c}=\frac{1}{2}\left(K_{o}\right)^{2}$, with $S_{c}^{\kappa}$ the surplus in zone 1a and $\widehat{S}_{c}$ the surplus in zone 2 . In zone 1a or 2 , incumbent could have incentives to increase the gas release price $\mathrm{r}$ for a given $\left(K_{o}, \alpha\right)$ pair. This increase in costs does not modify consumers' surplus. The increase in incumbent profit is only a trade off with competitor's profit, not with consumers' surplus. Competitor's supply costs increase and its profit are decreasing because it sells less quantity (the gas release quantity is active) at the same market price (market constraint is active) but its supply 
cost $\mathrm{r}$ increases (zone 2 in figure 1 ).

Lemma 2 As the market constraint is active, then a gas release price increase, linked with less efficient incumbent, does not impact consumers' surplus. The increase in incumbent's profit is only a trade off with competitor's profit.

Acknowledgement 3 The intuition of this lemma is the following. The increase in supply cost does not modify the quantity effect. The two operators still offer to consumer the same global quantity at the same price because the market constraint is always active. Operators' market shares are moving because competitor purchases less gas release quantities, as the gas release price increases. The incumbent sells the remaining of its supply.

If, for a given $\left(K_{o}, \alpha\right)$ pair, the market constraint is active, all incumbent's supplies are sold. With this $K_{o}$ level, moving from an equilibrium where the market constraint is active to a Cournot equilibrium (zone 3 in figure 1) deals with consumers' surplus losses. Quantities sold on the market was $q_{e}^{\kappa}+q_{o}^{\kappa}=$ $K_{o}$ or $\widehat{q}_{e}+\widehat{q}_{o}=K_{o}$, depending on the gas release constraint activity. If the equilibrium is the unconstraint Cournot one, then quantities are $q_{e}^{c}+q_{o}^{c}<K_{o}$. So, the consumer surplus decreases. In the other case, the consumer surplus increases. Incumbent has incentives to be efficient if the equilibrium is the unconstraint Cournot one to increase its profits (Clastres and David [2005]). For $\left(K_{o}, \alpha\right)$ pairs with $K_{o}<\frac{22}{3}$ and $\lambda_{e}<0$, if the equilibrium is in zone 3 (figure 1), then a decrease in incumbent costs or in gas release price could make the market constraint active. These incentives to efficiency improve the consumer surplus because consumption on the final market will be $K_{o}$ instead of $q_{e}^{c}+q_{o}^{c}$.

Lemma 4 At the unconstraint Cournot equilibrium with $K_{o}<\frac{2}{3}$, the incumbent has incentives to be efficient. These incentives improve consumers' surplus.

Acknowledgement 5 The intuition is the following. If the incumbent does not sell all its supply, it has incentives to decrease its costs. So, the competitor purchases more gas release quantities, but its sells and the market price decrease. The cost effect overcomes the reduction in final price and quantities it could sell. The incumbent earns more profit with this strategy (profits are decreasing in costs). As the competitor purchases and sells more gas release quantities, the market constraint becomes active. The effect on consumers' surplus is positive.

${ }^{2}$ For $K_{o} \geq \frac{2}{3}$, the market constraint is always inactive (Clastres and David [2005]). 
When the incumbent reduces its costs, so the gas release constraint becomes active for a large range of $\mathrm{K}_{o}$ or $\alpha$ values. The equilibrium could be $\left(q_{e}^{\kappa}, q_{o}^{m}\right)$. In this zone (zone 1b in figure 1), a modification of gas release price could not make the market constraint active because zones $1 \mathrm{~b}$ and 1a or 2 are complementary ones. Then, the consumer will prefer another equilibrium with higher quantities $K_{o}$ but this equilibrium could not be reach, except if incumbent gas supplies decrease. Furthermore, the $\left(q_{e}^{\kappa}, q_{o}^{m}\right)$ equilibrium is better than $\left(q_{e}^{c}, q_{o}^{c}\right)$ one for a given $\left(K_{o}, \alpha\right)$ pair. If the market constraint is inactive, the reaction function of the incumbent and competitor show that a reduction in incumbent quantities is compensated by a larger increase in competitor sales. The interest of consumer is to be in a context where competitor sales are greater. Competitor sales are maximum when the gas release constraint is active, that means when the equilibrium is $\left(q_{e}^{\kappa}, q_{o}^{m}\right)$ for a given $\left(K_{o}, \alpha\right)$ pair.

As a result, an increase in gas release price reduces the consumer's surplus because the gas release constraint becomes inactive. On the other hand, a decrease in gas release price increases competitor's sales that overcomes the diminution effect of incumbent's sales. A lower gas release price improves the consumer's surplus.

Lemma 6 If $K_{o}>K_{o}^{A}$, then an increase in gas release price reduces consumer's surplus if the equilibrium is $\left(q_{e}^{c}, q_{o}^{c}\right)$, and has no effect if the equilibrium stays $\left(q_{e}^{\kappa}, q_{o}^{m}\right)$. A lower gas release price improves or has no effect on consumers' surplus if we reach the equilibrium $\left(q_{e}^{\kappa}, q_{o}^{m}\right)$ or if the equilibrium is $\left(q_{e}^{c}, q_{o}^{c}\right)$.

Proof. See annex 1.

Acknowledgement 7 The intuition is the following. An increase in costs reduces the positive effect of quantities lowering the global offer of operators. On the other hand, if the gas release price is running low, the increase in competitor's sales compensates the reduction in incumbent's ones. This effect improves the consumers' surplus. If the competitor purchases all gas release quantities yet, then lowering gas release price only has an effect on operators' profits.

As we have shown it in Clastres and David [2005], if the incumbent has incentives to increases its costs, it does not impact consumers. This strategy has only an impact on competitor's profits.

Proposition 8 The effect of gas release price changes on consumer's surplus is ambiguous and rely on initial conditions of supplies $K_{o}$ and gas release proportion $\alpha$. Consumers are better of in markets where both supplies and gas release proportions are high. If the market is tight, then an increase in gas release price can reduce consumers' surplus reducing global quantities sold on the market.

Proposition 9 If the gas release constraint is active or both constraints are inactive, an increase in gas release price reduces consumer's surplus if the equilibrium is $\left(q_{e}^{c}, q_{o}^{c}\right)$ or if the equilibrium moves from $\left(q_{e}^{\kappa}, q_{o}^{m}\right)$ to $\left(q_{e}^{c}, q_{o}^{c}\right)$, has no 
effect on this surplus if the equilibrium is $\left(q_{e}^{\kappa}, q_{o}^{m}\right)$. Lowering this price in the same context increase the surplus if the equilibrium is $\left(q_{e}^{c}, q_{o}^{c}\right)$ or if the equilibrium moves from $\left(q_{e}^{c}, q_{o}^{c}\right)$ to $\left(q_{e}^{\kappa}, q_{o}^{m}\right)$, has no effect if the equilibrium stays $\left(q_{e}^{\kappa}, q_{o}^{m}\right)$.

Proof. See annex 1.

Acknowledgement 10 When we study the consumer's surplus, two effects appear. The first effect is the incumbent's cost (Clastres and David [2005]). The other effect is a quantity one. If incumbent's supplies are low, the cost effect has no impact because all supplies are sold. If supplies are in medium or high values, then an increase in costs reduces quantities sold on the market and has an impact on welfare. If costs decrease, so the consumers' surplus increase with quantities sold. The efficiency's gain could be profitable for the incumbent; its profits increase despite of the reduction of both its sales and final price.

If we suppose the regulator wants to maximise the consumer's surplus, then it must choose a gas release proportion such as all supplies are sold. If supplies are very high, the proportion must be chosen to let the competitor playing its Cournot strategy.

\subsection{Gas release and Welfare}

Let be $W=\Pi_{o}+\Pi_{e}+S_{c}=q\left(1-\frac{1}{2} q\right)-u K_{o}$ the welfare of the industry ${ }^{3}$. So, two effects appear :

- higher are quantities sold on the market, greater will be the welfare ${ }^{4}$;

- if the supply conditions $\left(K_{o}, u\right)$ are well negotiated ${ }^{5}$, the welfare will be high.

These two effects are complementary ones. If supply conditions are well negotiated, then the competitor must buy more quantities because the gas release price will be lower. So, the probability of equilibriums where gas release constraint or market constraint are actives will increase. When these equilibriums are played, the global quantity is greater than in Cournot zone, for a given level of supply $\mathrm{K}_{o}$. To show the intuition, we start from a given $\left(K_{o}, \alpha\right)$ pair such as the equilibrium is the unconstrained Cournot one. If the gas release price decreases, one of the constraints becomes active. We saw that if one constraint becomes active, quantities sold on the market increase ${ }^{6}$. These increases in

\footnotetext{
${ }^{3}$ As the demand function is $p(q)=1-q, q \leq 1$. The welfare is a concave function in $q$ and it is increasing for $q \leq 1$.

${ }^{4}$ For the study of quantities and equilibrium, see the precedent section.

${ }^{5} \mathrm{~A}$ small product $u K_{O}$ must say supply condition are efficients, or mean that the market size is small.

${ }^{6}$ The competitor wants to buy the minimum between its strategy $q_{e}^{\kappa}$ (the gas release constraint is active) or $\widehat{q}_{e}$ (the market constraint is active).
} 
quantities and in efficiency of supply conditions improve the welfare. On the other hand, for $\left(K_{o}, \alpha\right)$ pairs with $1-3 \alpha K_{o}<0$ and $K_{o}>K_{o}^{A}$, the unconstrained Cournot equilibrium is unique. If $r \rightarrow 0$, the limit of the activity of the GR constraint is $1-3 \alpha K_{o}=0$. If $\left(K_{o}, \alpha\right)$ are such that $1-3 \alpha K_{o}<0$ and $K_{o}>K_{o}^{A}$, so equilibrium is those with constraint inactive, for any GR price r. GR proportion $\alpha$ or incumbent's supplies $K_{o}$ are so high that competitors do not buy all GR quantities. Thus, we have the same conclusion as those in the section of consumers' surplus.

With a high gas release proportion and small supplies, the incumbent could have incentives to increase its supply cost (Clastres and David [2005]). This increase could be a less efficient renegotiation of long term supply contract with gas producers. This strategy does not impact sales on the market because the market constraint stays active but damages the welfare as it deteriorates supply conditions and competitors costs (Economides [1998]).

\section{The regulator and gas release proportion choice}

As we have seen before, gas release price are often set in line with costs, on non-discriminatory basis. It could be set at an average cost (as in England, Spain or Italy) or by an auction mechanism (Germany, France or Austria) with a ceiling price based on supply costs. Auction bids cannot be below this ceiling price (Clastres [2008]). If costs or ceiling price are lower, then gas release price could be weak ${ }^{7}$ and could have an increasing impact on welfare. However, it is very difficult to know how the gas release proportion $\alpha$ is set. We notice that its level is between 3 and $10 \%$ of the national natural gas consumption in a country but there is not any further information about it. On the other hand, we have seen that the gas release proportion could increase incentives for the incumbent to be less efficient to increase its profits (Clastres and David [2005]). This strategy has no impact on consumers' surplus but reduces the welfare because supply costs increase. The regulator must not set a so high gas release proportion to avoid this strategy for low supplies $\left(K_{o}<\frac{1}{2}\right)$. With a lower gas release proportion in a weak natural gas supply context, the regulator keep incentives to efficiency. If supplies are increasing, then incumbent's incentives to be les efficient progressively disappear and become inexistent if we are in the unconstraint Cournot equilibrium, i.e. when $K_{o}>\frac{1}{2}$ et $\mu_{o}^{\kappa}<0$. When supplies are higher $\left(K_{o}>\frac{1}{2}\right)$, the regulator, setting a smaller gas release proportion $\alpha$ such as $\lambda_{e}>0$ et $\mu_{o}^{\kappa}<0$, could lead the competition towards the equilibrium $\left(q_{e}^{\kappa}, q_{o}^{m}\right)$. Thus, the incentives are efficient one. If $K_{o} \in\left[\frac{1}{2}, \frac{2}{3}\right]$, the regulator could set $\alpha$ as $\mu_{o}^{\kappa}>0$.Quantities sold on the market would be greater (all $K_{o}$ supplies are sold) but the incumbent could have incentives to be less efficient, with a negative impact on welfare.

After this short discussion, we assume that regulator wants to maximize the

\footnotetext{
${ }^{7}$ In an auction mecanism, it depends on bids.
} 
welfare function $W$ seen above and not only the consumer's surplus. We have seen that gas release price is set in line with costs or by an auction mechanism. So, $\alpha$ will be the variable that the regulator could set to maximise welfare. If $K_{o}<\frac{1}{2}$, then all gas release proportion $\alpha$ maximises the welfare because the market constraint is always active. The supply costs are the only variable that affects the welfare. So, the regulator has incentives to set a small $\alpha$ to restore incentives to efficiency. If $\mu_{o}^{\kappa} \geq 0$, the regulator sets $\alpha$ as $\mu_{o}^{\kappa}=0$. Doing so, all incumbent's profits become decreasing and continuous function in $\mathrm{u}$ for $u \in] 0,1]$. The incumbent has again incentives to renegotiate for the best its supply costs when renegotiation rounds with producers take place along the lifetime of the long term take or pay contract. Setting the gas release proportion $\alpha$ at $\mu_{o}^{\kappa}=0$ level for $K_{o}<\frac{2}{3}$, the regulator is certain to maximise welfare ${ }^{8}$ and restore incentives for the incumbent to be more efficient to increase its profits. On the other hand, if $K_{o}>\frac{2}{3}$, then, for any gas release price, the equilibrium are $\left(q_{e}^{\kappa}, q_{o}^{m}\right)$ if $\lambda_{e}>0$ et $\left(q_{e}^{c}, q_{o}^{c}\right)$ if $\lambda_{e}<0$. The regulator decides to set $\alpha$ to achieve the equilibrium $\left(q_{e}^{c}, q_{o}^{c}\right)$ for a given $\left(K_{o}, r\right)$ pair. Actually, with an $\alpha$ leading to the equilibrium $\left(q_{e}^{\kappa}, q_{o}^{m}\right)$ for a given $\left(K_{o}, r\right)$ pair, the competitor is constrained. It would like to buy more gas release quantities at price $\mathrm{r}$ and it would be possible because all $\mathrm{K}_{o}$ supplies are not sold $\left(q_{e}^{\kappa}+q_{o}^{m}<K_{o}\right)$. The reduction in competitor's sales (it sells $q_{e}^{\kappa}$ instead of $q_{e}^{c}$ ) is greater than the increase in incumbent's sales $\left(q_{o}^{c}\right.$ to $\left.q_{o}^{m}\right)$. Thus, global quantities sold on the market decrease for a constant $K_{o}$ supply level. This effect reduces welfare. The welfare is greater if regulator chooses a greater gas release proportion $\alpha$ if supplies are high and if the gas release prise could not modify the equilibrium $\left(q_{e}^{c}, q_{o}^{c}\right)$.

With a high gas release proportion, the risk of tacit collusion between firms could increase. So, the regulator must be watchful to incentives to collusion setting the gas release proportion. Literature on tacit collusion shows that firms could adopt sustainable collusive behaviours if there exist capacities of production (Green and Newberry [1992], Crampes and Creti [2005]) and if these capacities of production are symmetric (Pénard [1997], Bernheim and Whinston [1990]). So, a high level of gas release price reduces the difference between capacities of production of competitors and incumbent. This reduction increases the sustainabilty of collusion. However, if the regulator sets a small gas release proportion, the difference in capacities always exists and could reduce the risk of collusion (Compte, Jenny and Rey [2002], Ivaldi and alii [2003]).

Proposition 11 If supplies are low, $K_{o}<\frac{1}{2}$, the regulator could choose any proportion in $] 0,1]$ but it does not be so high to keep incumbent incentives to efficiency. If supplies are higher, $K_{o} \in\left[\frac{1}{2}, \frac{2}{3}\right]$, the regulator maximizes welfare setting a gas release proportion as $\mu_{o}^{\kappa}=0$. If supplies are greater, $K_{o}>\frac{2}{3}$, the regulator set a gas release proportion such as $\lambda_{e}<0$.

Proof. See annex 2.

\footnotetext{
${ }^{8}$ All supplies $\mathrm{K}_{o}$ are sold.
} 
Acknowledgement 12 The regulator, setting $\alpha$, introduces a trade off between incumbent and competitor profits. The welfare is maximum if quantities sold on the market are high and if supplies conditions, i.e. cost $u$ and level $K_{o}$, are well negotiated. When supplies in a country are low, all contracted quantities are sold. So, to maximize welfare, the only solution for the regulator is to improve incumbent efficiency. More the incumbent is efficient, lower will be the cost of supplies $u$ and the gas release price $r$. So, the gas release proportion $\alpha$ must not be so high to avoid countervailing incentives : the incumbent could have incentives to increase its costs for high gas release proportions (Clastres and David [2005]). When supplies are in medium values, the regulator could use both the gas release proportion and the efficiency of the incumbent to improve welfare. Its strategy is to assess $\alpha$ as all supplies $K_{o}$ are sold and incumbent has incentives to reduce its costs ( $\alpha$ as $\left.\mu_{o}^{\kappa}=0\right)$. So, for these values of $\alpha$, the competitor purchases all gas release quantities and incumbent sells the remaining of its supplies $(1-\alpha) K_{o}$. As the price on final market is constant and competitor purchases all gas release quantities, the incumbent could improve its profits and the welfare if supply costs decrease. If supplies are high, the regulator sets $\alpha$ to maximise sales on the market and to benefit from incentives to efficiency. The incumbent, in this case, has incentives to be efficient because competition has an impact on its profits. Each unit of supply it could not sell decrease its profits. The regulator could set a gas release proportion greater than in other cases, notably if all supplies $K_{o}$ could be sold.

\section{Conclusion}

We have assumed that supplies $K_{o}$ were not very adaptable. On the other hand, we have seen that the incumbent has an influence on gas release price because they are based on supply costs. This costs could be altered if incumbent, in a round of renegotiation of supply long term take or pay contracts, is not efficient. The regulator sets both the gas release proportion and the regulation of gas release price (equal to costs $\mathrm{u}$ or to and auction bid with costs as ceiling price below which gas release quantities are not sold).

When supplies are low (blue shaded area in figure 2), regulator, setting a low gas release proportion, increases incumbent incentives to efficiency. This increase in efficiency does not modify global quantities sold on the market, so the consumer surplus is constant, but increase the welfare, because supply conditions are better.

When supplies are higher, so the regulator, setting a gas release proportion as a function of supplies (red line in figure 2), makes the incumbent efficient. All supplies $\mathrm{K}_{o}$ are sold, so the consumer surplus is maximum and the welfare increase because of high value of quantities and incumbent efficiency. If $K_{o} \in$ $\left[\frac{1}{2}, \frac{2}{3}\right]$, the regulator has a dominant strategy : setting a gas release proportion as $\mu_{o}^{\kappa}=0$. The red line (figure 2) could be extended to the intersection point, solution of the system $\left\{\begin{array}{c}1-3 \alpha K_{o}=0 \\ K_{o}=\frac{2}{3}\end{array}\right.$. 
When supplies are greater, so several screenplays exist. Regulator maximises the welfare and surplus setting $\alpha$ as no constraint is active. Actually, setting a lower value of $\alpha$, the gas release constraint is active and modifies competitor strategy. It purchases less quantities and this diminution is more important than the increase in incumbent sales. So, the surplus and welfare dropped. Regulator, setting $\alpha$ a higher value of $\alpha$, maximises surplus and welfare. Effectively, if supplies are in medium values (green shaded area in figure 2), the incumbent has incentives to be efficient. This increase in efficiency reduces the gas release price and the market constraint becomes active. Surplus and welfare increase because of more quantities with low costs sold on the market. If the efficiency cannot be modified, then quantities sold are greater than those which smaller gas release proportion. In the other case, a small gas release proportion makes the gas release constraint active. Competitor purchases fewer quantities that the increase in incumbent's sales does not compensate. Losses in surplus and welfare appear. If $K_{o}$ is greater (yellow shaded area in figure 2), then efficiency increase surplus and welfare. Competitor purchases more quantities (the gas release price is lower) until the gas release constraint becomes active. This increase is greater than the incumbent's sales reduction so, as there are improvements in supply conditions, welfare and surplus are improved. Finally, when gas penetration in primary consumption is weighty (yellow squared area in figure 2), so, for any gas release price $r$, this case maximises welfare. Competitor purchases greater gas release quantities because the gas release constraint is inactive. Here again, welfare and surplus are improved with quantities and efficiency effects.

\section{Bibliography}

Breton M. et Zaccour G., 2001, « Equilibria in an asymmetric duopoly facing a security constraint », Energy Economics, n $\square 23$, pp 457-475

Bernheim B.D. etWhinston M.D., 1990, "Multimarket contact and collusive behaviour ", Rand Journal of Economics, vol 21, issue 1, august 1990, pp 1-26

Clastres C., 2008, "An analysis of gas release experience in Europe", Mimeo, 2008

Clastres C. and David L., 2005, "Strategies of an incumbent in a context of Gas Release", Working paper n—05.09.60, CREDEN.

Compte O., Jenny F. et Rey P., 2002, « Capacity constraints, mergers and collusion », European Economic Review, n—46, pp 1-29

Crampes C. et Creti A., 2005, « Capacity Competition in ElectricityMarkets », Economia delle fonti di energia e dell'ambiente, $\mathrm{n} \varpi 2$ 2, 2005, p. 59-83

Economides, N. (1998). "The incentive for non-price discrimination by an input monopolist." International Journal of Industrial Organization. 16: 271284

Green R. et Newberry D., 1992, « Competition in the British Electricity spot Market », Journal of Political Economy, vol. 100, n $\square$ 5, pp 929-953

Green R., 2007, "US Regulation and Competition Policy among the Energy Utilities", December 2007, RePec Working Paper 
Figure 2 : Areas of maxima welfare and consumer surplus

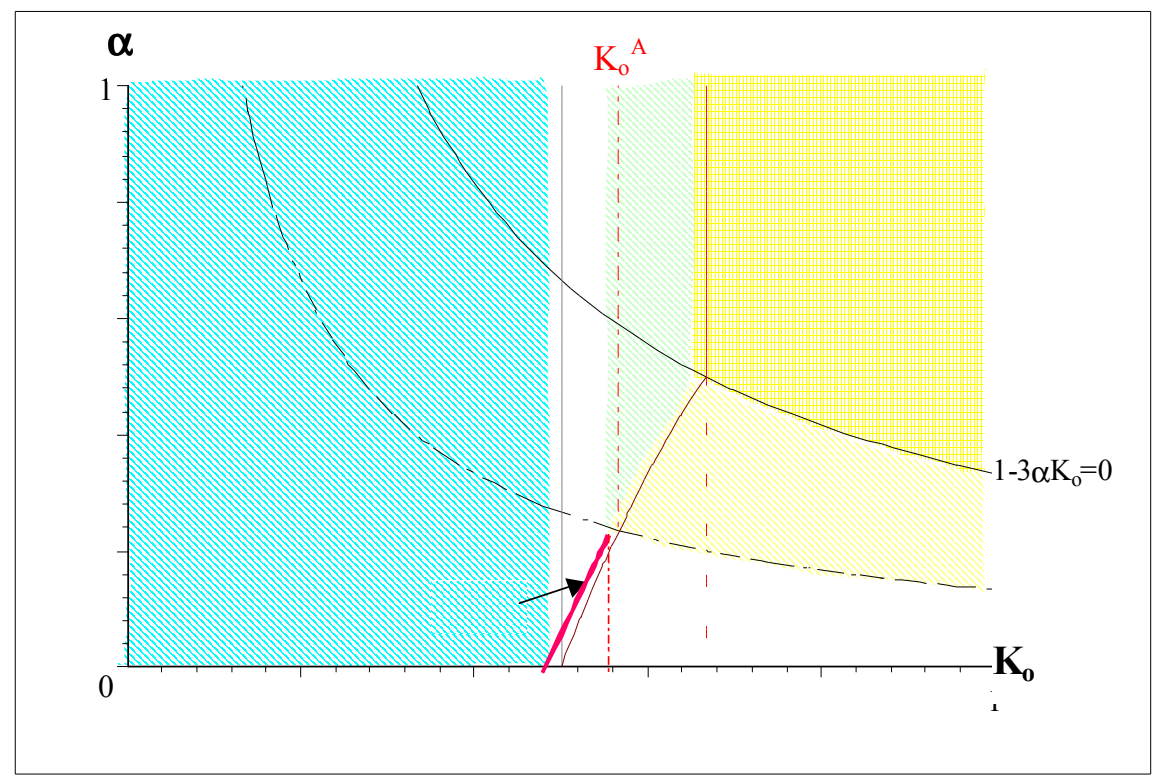

Figure 2: 
IvaldiM., Jullien B., Rey P., Seabright P., et Tirole J., 2003, "The Economics of Tacit Collusion", Final Report for DG Competition, European Commission, March 2003

Penard T., 1997, « Choix de capacités et comportements stratégiques. Une approche par les jeux répétés », Annales d'Economie et de Statistique, n耳46, pp 203-224

Schankerman M., 1996, « Symetric regulation for competitive telecommunications », Information Economics and Policy, n匹8, pp 3-23

\section{Annex 1 : Consumer surplus}

With our linear demand $p(q)=1-q$, the consumer surplus $S_{c}=\frac{1}{2} q^{2}$ is an increasing function of $q$. Consumers prefers if all supplies are sold, so equilibrium in zones Ia or II for a given $\left(K_{o}, \alpha\right)$ pair. Quantities in zone Ib are less importants for a given $K_{o}\left(q_{e}^{\kappa}+q_{o}^{\kappa}=\widehat{q}_{e}+\widehat{q}_{o}=K_{o}>q_{e}^{\kappa}+q_{o}^{m}\right)$. However, if the equilibrium is in zone Ia or II, it is not possible to reach zone Ib if r modified. These zones are complementary ones and being in zone Ib depends on initial conditions $\left(K_{o}, \alpha\right)$, and on $r$ values.

The incumbent could modify the equilibrium with the negociation of its costs of supply u. It could move from zone Ib to zone III and inversely. However, incentives goes with efficiency. So, we will study if it is possible that consumer surplus is higher in zone Ib rather than in zone III. We will compare consumer surplus in zones Ib and III for all $r$. Two equilibrium are available :

- The Cournot equilibrium $\left(q_{e}^{c}, q_{o}^{c}\right)$ with $S_{c}^{c}=\frac{1}{18}(r-2)^{2}$ as consumer surplus;

- the equilibrium with the gas release constraint active $\left(q_{e}^{\kappa}, q_{o}^{m}\right)$ with $S_{c}^{\kappa, m}=$ $\frac{1}{8}\left(\alpha K_{o}+1\right)^{2}$ as consumer surplus.

Moving from $\left(q_{e}^{c}, q_{o}^{c}\right)$ towards $\left(q_{e}^{\kappa}, q_{o}^{m}\right)$ implies a change in gas release price $\mathrm{r}$, for a given $\left(K_{o}, \alpha\right)$ pair. If gas release price decrease, competitor could buy more gas release quantities and to bind the gas release constraint, th incumbent always playing its best reply function. If gas release price increase, the intuition is the contrary one. If we call $q_{o}\left(q_{e}\right)=1-2 q_{e}-r$ the competitor's Cournot reaction function and $q_{o}\left(q_{e}\right)=\frac{1}{2}-\frac{1}{2} q_{e}$ those of the incumbent, the explanation of equilibrium changes is in th following figure. 


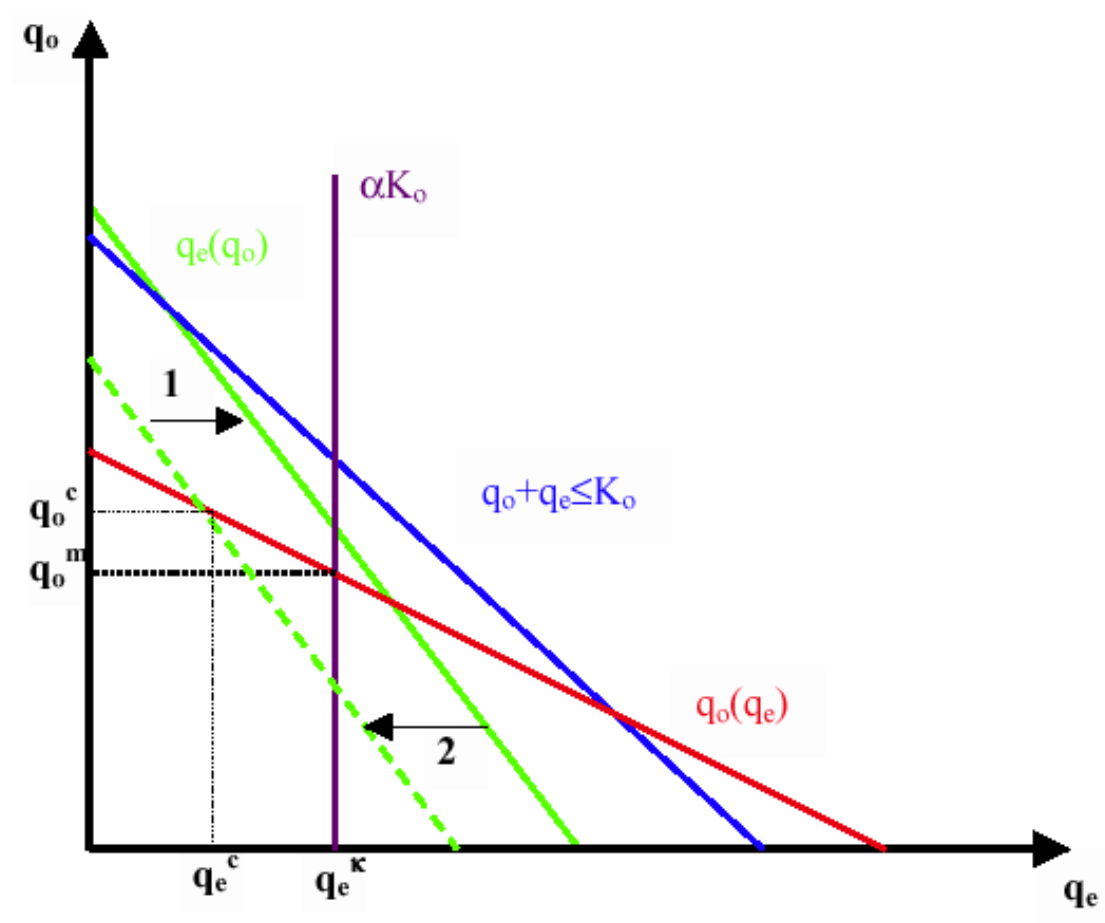

The arrow 1 indicates the shift of competitor's Cournot reaction function if $r$ decreases, i,e $\left(q_{e}^{c}, q_{o}^{c}\right)$ towards $\left(q_{e}^{\kappa}, q_{o}^{m}\right)$. The arrow 2 indicates the same shift but with an increase in r, i,e $\left(q_{e}^{\kappa}, q_{o}^{m}\right)$ towards $\left(q_{e}^{c}, q_{o}^{c}\right)$.

We can distinguish two cases. First, if gas release price variations are too low to modify the equilibrium, then :

- if the equilibrium is $\left(q_{e}^{c}, q_{o}^{c}\right)$, an increase (decrease) in gas release price reduces (increases) quantities sold on the market. So, according to reaction functions, if gas release price decreases, the increase in competitor's sales overcomes the decrease in incumbent'ones. Consumers surplus increases. If gas release price increases, so inversely, consumers surplus is decreasing because of competitor's sales are not compensated by incumbent ones.

- We could have the same idea if the equilibrium is $\left(q_{e}^{\kappa}, q_{o}^{m}\right)$, except that the consumer surplus is invariant in $\mathrm{r}$ variations, as quantities are independant in r. The only effect is on operator's profits.

Second case, if gas release price variations could change the equilibrium zone, we could move from $\left(q_{e}^{\kappa}, q_{o}^{m}\right)$ towards $\left(q_{e}^{c}, q_{o}^{c}\right)$. As we can see in the precedent figure, an increase in $\mathrm{r}$ leads to reduction of $q_{e}$ from $q_{e}^{\kappa}$ towards $q_{e}^{c}$ and an increase in $q_{o}$ from $q_{o}^{m}$ to $q_{o}^{c}$. A variation of $q_{e}$ is not compensated by variations of $q_{o}$, so quantities sold on the marcket decrease. So, an increase in gas release 
price reduces consumer's surplus moving from $\left(q_{e}^{\kappa}, q_{o}^{m}\right)$ towards $\left(q_{e}^{c}, q_{o}^{c}\right)$. For the same reason, a decrease in gas release price increase consumer's surplus, for a given $\left(K_{o}, \alpha\right)$ pair.

\section{Annex 2 : Maximisation of Welfare by regu- lator}

The welfare is $W=(1-q) q-u K_{o}+\frac{1}{2} q^{2}=q-\frac{1}{2} q^{2}-u K_{o}$.

If $K_{O}<\frac{1}{2}$, the market constraint is active. So the welfare in independant in $\alpha$ but depends on supply levels $K_{o}$ and on supply costs $u$.

If $K_{o} \in\left[\frac{1}{2}, \frac{2}{3}\right]$, all equilibriums are possibles. So we have following quantities and welfares :

- $q^{\kappa}=\widehat{q}=K_{o} \Rightarrow W^{\kappa}=W^{\kappa, m}=K_{o}-\frac{1}{2} K_{o}^{2}-u K_{o}$

- $q^{\kappa, m}=\frac{1}{2}+\frac{1}{2} \alpha K_{o} \Rightarrow W^{\kappa, m}=\left(\frac{1}{2}+\frac{1}{2} \alpha K_{o}\right)-\frac{1}{2}\left(\frac{1}{2}+\frac{1}{2} \alpha K_{o}\right)^{2}-u K_{o}=$
$\frac{3}{8}+\frac{1}{4} \alpha K_{o}-\frac{1}{8} \alpha^{2} K_{o}^{2}-u K_{o}$

- $q^{c}=\frac{2}{3}-\frac{1}{3} u \Rightarrow W^{c}=\left(\frac{2}{3}-\frac{1}{3} u\right)-\frac{1}{2}\left(\frac{2}{3}-\frac{1}{3} u\right)^{2}-u K_{o}=\frac{4}{9}-\frac{1}{9} u-\frac{1}{18} u^{2}-u K_{o}$

The first and third welfare are independant in $\alpha$. They depends on supply conditions $u K_{o}$. But, the second welfare is a function of $\alpha$. Its maximisation leads to :

$\underset{\alpha}{\operatorname{Max}} W^{\kappa, m} \Rightarrow \frac{d W^{\kappa, m}}{d \alpha}=\frac{1}{4} K_{o}-\frac{1}{4} \alpha K_{o}^{2}=0 \Leftrightarrow \alpha=\frac{1}{K_{o}}$.

$\frac{d^{2} W^{\kappa, m}}{d \alpha^{2}}=-\frac{1}{4} K_{o}^{2}<0$ so $W^{\kappa, m}$ is a concave fucntion of $\alpha$ and $\alpha=\frac{1}{K_{o}}$ is the maximum of this function. We are in the equilibrium zone II, where $\mu_{o}^{\kappa} \leq 0 \Leftrightarrow 1-2 K_{o}+\alpha K_{o} \leq \alpha \Leftrightarrow \alpha<\alpha_{o}=\frac{2 K_{o}-1}{K_{o}}$. If $\alpha=\frac{1}{K_{o}}$ could be reach, it must be such as $\alpha<\alpha_{o} \Leftrightarrow \frac{2 K_{o}-1}{K_{o}}-\frac{1}{K_{o}}>0 \Leftrightarrow 2 \frac{K_{o}-1}{K_{o}}>0$, wrong because $K_{o}<\frac{2}{3}$ (the limit of the existence of zone 2 is such as $\widehat{\mu}_{o}>0 \Leftrightarrow K_{o}<\frac{2-r}{3}$ with the upper limit when $r=0$, i,e $K_{o}<\frac{2}{3}$ ) so this maximum could not be reached. We are in the increasing part of the welfare. The regulator sets $\alpha_{o}$ to maximise the welfare. We are on the curve $\mu_{o}^{\kappa}=0$, with continu and decreasing profit and no incentives to increase costs of supply $u$.

If $K_{o}>\frac{2}{3}$, so two equilibriums are only available, for all $\mathrm{r}$ values. these two equilibriums are $\left(q_{e}^{\kappa}, q_{o}^{m}\right)$, only the gas release constraint is active, or $\left(q_{e}^{c}, q_{o}^{c}\right)$, the unconstrained Cournot equilibrium. Supplies $K_{o}$ are high enought to make the market constraint inactive. The regulator maximise the welfare setting a gas release proportion such as $\lambda_{e}<0$. For all $r$, setting a gas release proportion such as $\lambda_{e}>0$, the regulator could constraint competitor. The competitor wishes 
to buy $q_{e}^{c}$ but, as a lower value of $\alpha$, it could only buy $q_{e}^{\kappa}$. So, quantities sold on the market are lower. If gas release proportion is higher, the equilibrium is $\left(q_{e}^{c}, q_{o}^{c}\right)$. Competitor does not buy all gas release quantities, the incumbent plays its Cournot best reply function but the quantities sold on the market are higher. The following figure illustrates this case.

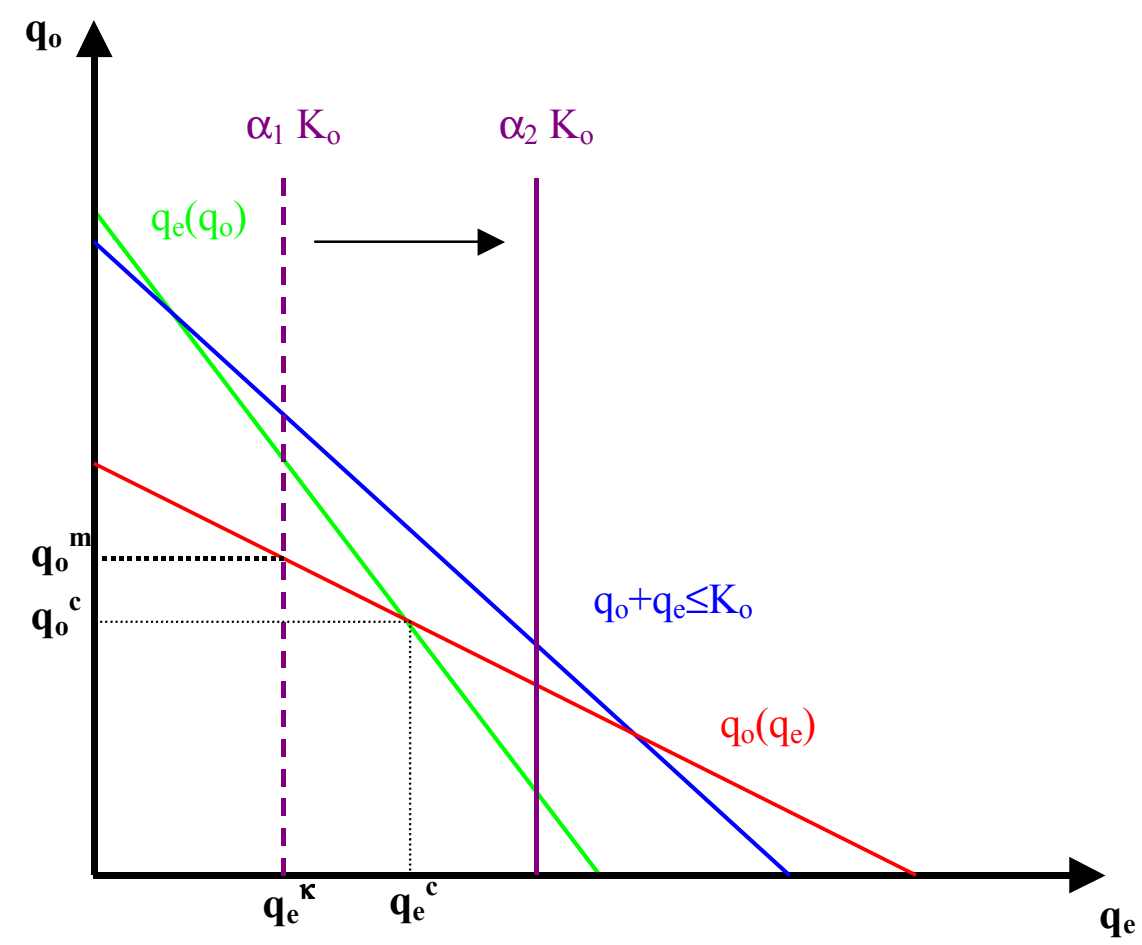

If $K_{o} \geq \frac{2}{3}$ and if gas release price is constant, if the regulator chooses $\alpha=\alpha_{1}$ with $\alpha_{1}$ such as $\lambda_{e}>0$, so the equilibrium is $\left(q_{e}^{\kappa}, q_{o}^{m}\right)$. If, the regulator sets $\alpha=\alpha_{2}$ with $\alpha_{2}$ such as $\lambda_{e}<0$, so the equilibrium is $\left(q_{e}^{c}, q_{o}^{c}\right)$. For the same $\left(K_{o}, r\right)$ pair, the gas release constraint is inactive and competitor's quantities, thus total quantities sold on the market, increase. As the incumbent has incentives to be efficient, the cost of supply, and r, could decrease. So, if gas release proportion is such as $\lambda_{e}<0$ with $1-3 \alpha K_{o}>0$, a reduction in $\mathrm{r}$ could modify the equilibrium from $\left(q_{e}^{c}, q_{o}^{c}\right)$ to $\left(q_{e}^{\kappa}, q_{o}^{m}\right)$. Thus, the competitor could move from an equilibrium wherre the gas release constraint is inactive to an equilibrium where it becomes actives, increasing quantities and welfare. 